\title{
Adam Possamaï, Religion and Popular Culture. A Hyper-Real Testament
}

Bruxelles, PIE-Peter Lang, 2005, 161 p.

\section{Régis Dericquebourg}

\section{OpenEdition}

\section{Journals}

Édition électronique

URL : http://journals.openedition.org/assr/4026

DOI : $10.4000 /$ assr.4026

ISSN : $1777-5825$

Éditeur

Éditions de l'EHESS

Édition imprimée

Date de publication : 1 décembre 2006

Pagination : 115-283

ISBN : 2-7132-2124-2

ISSN : 0335-5985

\section{Référence électronique}

Régis Dericquebourg, «Adam Possamaï, Religion and Popular Culture. A Hyper-Real Testament»,

Archives de sciences sociales des religions [En ligne], 136 | octobre - décembre 2006, document 136-89, mis en ligne le 14 février 2007, consulté le 21 septembre 2020. URL : http://journals.openedition.org/ assr/4026 ; DOl : https://doi.org/10.4000/assr.4026

Ce document a été généré automatiquement le 21 septembre 2020

(c) Archives de sciences sociales des religions 


\title{
Adam Possamaï, Religion and Popular Culture. A Hyper-Real Testament
}

\author{
Bruxelles, PIE-Peter Lang, 2005, 161 p.
}

\section{Régis Dericquebourg}

1 Le succès du Da Vinci Code (Dan Brown, 2003) a montré l'engouement pour un ésotérisme dilué dans la culture populaire. À partir d'informations recueillies dans les années 1996-97 sur Internet (cyber ethnographie), le sociologue australien Adam Possamaï fait une autre constatation: des productions littéraires, comme les bandes dessinées de science fiction ou de chevalerie médiévale dont le marché est relativement restreint, peuvent être une source d'inspiration pour créer de nouvelles formes de religiosité adaptées à une post-modernité qui a remodelé le paysage religieux et spirituel. Dans son livre, il se propose d'apporter une théorie de cette culture comme l'ont fait Baudrillard et Lipoveski pour la post-modernité. L'auteur se réfère à Max Weber pour analyser le sens que les acteurs sociaux donnent à leurs activités en tant qu'agents portés par des déterminants socioculturels et aussi - l'auteur ne le dit pas pour sa tentative de typification d'une forme de spiritualité.

2 Pour A. Possamaï, du point de vue religieux, la post-modernité est marquée par l'avènement d'un «hyper consumérisme ». On assiste à ce que Danièle Hervieu-Léger a remarqué : un nomadisme et un "bricolage" spirituel avec un goût pour les expériences personnelles, tout ceci étant dans le ton du capitalisme néo-libéral, de la globalisation et d'une culture de masse dans laquelle les médias imposent une réalité dématérialisée qualifiée d'hyper consumérisme religieux. Ce dernier, typique du capitalisme tardif, donnerait une identité à des groupes ou des individus qui suivent une voie spirituelle en dehors des Églises et à des groupes religieux minoritaires déjà devenus classiques.

3 Les acteurs de cette spiritualité sont engagés dans la consommation d'une culture populaire. Ils se l'approprieraient en en retenant certains thèmes et en éliminant d'autres. Il en résulterait ce que l'auteur appelle une religion hyperréelle (qualifiée de simulacre de religion) créée à partir de la culture populaire qui est une source d'inspiration pour des croyants consommateurs à un niveau métaphorique. Ce type de 
spiritualité est à l'état embryonnaire mais l'auteur prévoit son expansion dans un avenir proche. En puisant à d'autres sources que les grandes traditions religieuses, la religion hyperréelle véhiculerait indirectement une protestation contre celles-ci. D'autre part, en mettant en scène le combat victorieux des super-héros contre le mal (le terrorisme par exemple), elle donnerait un sentiment de sécurité et donc serait adaptée à une "société du risque ». Elles participeraient aussi au réenchantement du monde. Un exemple de ce type de religion est le jedisme (inspiré par le Jedi de Star Wars). En Grande-Bretagne, le census de 2001 révèle que 390000 personnes $(0,7 \%)$ de la population se déclarent suiveurs de la « foi Jedi ».

En somme l'auteur isole et étudie une réalité peu traitée à l'exception de quelques thèses françaises sur l'appropriation de vulgates ésotériques et satanistes à travers des productions littéraires ou audiovisuelles (groupes musicaux). Son livre fourmille de remarques intéressantes qui ont été développées dans ses articles. Par exemple, il propose de rassembler sous le nom de perenisme les mouvements liés au développement personnel et tendant vers le supra-empirique qu'il définit comme une spiritualité interprétant le monde d'une manière moniste. Ses acteurs tentent de développer leur potentiel humain éthique en cherchant des connaissances d'ordre spirituel principalement sur le «self». Ces mouvements se distinguent des Églises de guérison et des religions de santé. D'autre part, il insiste sur la notion importante d'appropriation. Cette notion qui vaut pour la manière dont les croyants filtrent les préceptes de leurs mouvements vaut aussi pour la manière dont les individus peuvent s'approprier les biens culturels en fonction du sens qu'il veulent donner à leur existence et en fonction des manières de répondre aux angoisses provoquées par la vie collective.

Nous conclurons cette recension par deux remarques : 1 - Le titre du livre situe les mythes de la culture populaire dans la religion par l'appropriation qu'en fait un certain public. Comment qualifier ce nouveau type de religion. A-t-on affaire à du religieux analogique ? Ou à un simulacre de religion? Ou encore à un substitut de religion? Que nous enseigne du point de vue sociologique la spiritualisation de récits et de héros de bande dessinée ? Il semble que la quête de spiritualité soit toujours présente et passe par des voies imprévues; 2 - Bien que l'auteur situe la mouvance qu'il étudie dans la post-modernité en se référant à J. Baudrillard, G. Lipoveski et à J.-F. Lyotard, son étude nous renvoie à une interrogation à propos de celle-ci. Les déterminants sociaux de ces nouvelles formes de religiosités n'appartiennent-ils pas à une accélération du processus de la modernité que Jean-Paul Willaime appelle l'hypermodernité plus qu'à une postmodernité dont le préfixe pourrait laisser entendre que l'on se trouve dans une nouvelle phase de la société qui a radicalement rompu avec celle-ci et qu'on aurait de la peine à qualifier? L'ouvrage de Adam Possamaï mérite d'être lu à la fois pour ce qu'il apporte mais aussi pour les pistes de réflexion qu'il propose. 